\title{
Impact of Excellence Model Awards on Stock Market Performance - A Study of Selected Indian Companies
}

\author{
${ }^{1}$ Prof Rajendra K Gupta, ${ }^{2}$ Prof (Dr.) Harsh Dwivedi \\ ${ }^{1}$ (SoBM, Jaipur National University), ${ }^{2}$ (Poddar Institute of Management) Jaipur
}

\begin{abstract}
Business excellence awards have been commissioned in many countries based on national excellence models. One such important model is Malcolm Baldrige award in USA. In India CII-Exim excellence award is given to best companies. However in India a few companies have so far qualified for such excellence awards. Globally many studies have indicated that winning such quality or excellence wards give superior returns in stock price performance. But the studies have mixed results. This paper is based on research conducted in Indian companies regarding their price performance in stock market for a period of 7 years. A new variable Consistency Score has also been used as an indicator of consistent financial performance by companies using best practices.
\end{abstract}

Key words: Stock performance, business excellence, consistency score, stock market returns, excellence awards

\section{Introduction:}

Achieving excellence has become imperative for companies to reach a world class status which shall make them strong enough to become globally competitive and withstand changes in dynamic and complex environment and also be able to meet rising expectations of shareholders. The end result of the efforts of companies is always gauged by shareholders in terms of stock performance in market which gives them consistently superior returns over ordinary companies or over the general market indices like Nifty 50 or BSE 100. A number of studies have been conducted in various countries that claim that Excellence award winning companies give superior returns to shareholders. One such study by Hendricks and Singhal (2000) conducted on Malcolm Baldrige award wining companies in USA is quite popular and frequently referred in literature.

As a part of doctoral research project on 'Factors determining excellence in Indian Companies', we collected data of CII-EXIM excellence award companies in India up-to 2011 to study effect of excellence practices on shareholders returns.

\section{The Research Model}

One parameter of excellence is better financial reward earned for shareholders in terms of rise in stock price relative to the broad benchmark indices. Here we have two choices for comparative study for outperformance. One is NSE 500 index, a broad based index that covers $95 \%$ of market capitalization in India, and other is our standard NSE Nifty 50, popularly called Nifty. Since CNX500 and CNX 50 both show same trend in performance, we have taken nifty fifty and the companies' stock performance for comparison purposes. So if an investor puts in Rupee 1 in Nifty index future and the same amount in an excellence award winning company, how the investor gets stock market performance for the invested amount in terms of $\%$ growth/decline, is subject of this study.

A period of 7 years has been taken for study. This is considered good enough time period even for long term investment point of view as well as to see comparative performance of markets and the company stocks of our interest. Hence we have plotted graphs of stock prices of companies with excellence awards/prizes and the general stock index Nifty 50 starting 18-9-2005. These graphs are auto generated by database of NSE processed by professional financial advisory service Investar, Mumbai.

The starting level price change for both the plots is of course, $0 \%, 7$ years ago. The changes are being measured in term of percentage change in price at any given date as compared to zero level date.

The other dimension we have considered for excellence is continuous growth of revenue and profits registered by the company. This is natural outcome expected when a company practices excellence. For this we designed a new variable as explained below:

\section{Consistency Score $(\mathbf{C S})$}

Since conventional financial measures like ROI vary from industry to industry, we have taken CAGR of companies as a measure free of external conditions and we designed this new score called Consistency score: In last 5 years results there are 4 blocks. For a company registering positive growth in each block, 1 point is given to each of Sales growth, Gross profit growth and PAT growth, respectively. These three criteria take care 
Impact of Excellence Model awards on stock market performance - A study of selected Indian

of entire structuring and capital management capability of the firm besides its market share and revenue growth. Hence a firm can get maximum $4 \times 3=12$ points on consistency score and minimum of 0 .

For example: The financial data of 5 years (2007-2011) for two companies from our sample is given

Table 1: Example of financial data used to compute consistency score

\begin{tabular}{|c|c|c|c|c|c|c|}
\hline Tata Power Co. Ltd & Revenue & $5,059.31$ & $6,381.75$ & $7,868.58$ & $\underline{7,379.85}$ & $\underline{7,092.94}$ \\
\hline & GP & $1,067.43$ & $1,428.22$ & $1,751.32$ & $2,143.84$ & $1,720.26$ \\
\hline & PAT & 696.8 & 869.9 & 922.2 & 947.65 & 970.01 \\
\hline & EPS & 35.21 & 39.41 & 41.65 & 39.93 & 40.87 \\
\hline & FV & Rs 10/- & & & & \\
\hline TCS & Revenue & $15,156.52$ & $18,979.67$ & $21,947.7$ & $23,222.0$ & $29,770.14$ \\
\hline & GP & $4,517.52$ & $5,466.06$ & $5,564.59$ & $6,849.27$ & $9,258.26$ \\
\hline & PAT & $3,757.29$ & $4,508.76$ & $4,696.21$ & $5,618.51$ & $7,569.99$ \\
\hline & EPS & 38.39 & 46.07 & 47.99 & 28.71 & $\underline{38.68}$ \\
\hline
\end{tabular}

FV Rs 1/-

In Tata Power case, the revenue has dipped in 2010 and 2011 and hence it gets only 2 marks for rising revenue in 2007-2008 and 2008-2009 periods only. In Case of GP, there is dip in only 2011. Hence it gets score of 3 out of 4 as it has positive growth in 3 periods. Since PAT is growing through out, it gets 4 marks. Hence total consistency score is 9 , out of maximum possible 12 .

Similarly for Tata Consultancy Services the Consistency score are 12 out of 12 since it has continuing positive growth in all three parameters in all 4 blocks of years. This way we calculated Consistency score, CAGR Revenue, and CAGR profit for all sample companies using last 5 years results from Indiaearnings.com, and verified from data found on company website and CMIE (Centre for Monitoring Indian Economy, Delhi) databases.

While consistency score depends on internal strength and management of firm, the CAGR still depends on macro factors, nature of industry and cyclic variations. Hence the CAGR rates may not hold validity for crosssector comparisons.

\section{Impact of Excellence Award/Prize}

\section{Award Winners}

Table 2 List of CII EXIM winners in India (Source: CII Center of Excellence, Bangalore)

2009 - Bosch Limited, Diesel Systems business - Started outperforming since 2010 (Non sample)

2006: Tata Consultancy Services Limited -Started Outperforming July 2010 onwards (Consistency score- 12)

2005: Commercial Vehicle Business Unit (CVBU), Tata Motors Limited -Started Outperforming August 2010 onwards (Consistency score 8.0)

2002: Infosys Technologies Limited -Up-to December 2009 underperforming. Now (Consistency score-11.0)

2000: Tata Iron \& Steel Co. Limited - Under performing since August 2008 (Consistency score- 11.0)

1998: Maruti Udyog Limited - Outperforming since Jan 2009

1997: Hewlett Packard (India) Limited - Not listed (Non sample)

Prize Winners

2010: Crompton Greaves India Ltd - Out performing since May 2009.Current Neutral (Consistency score 12.0)

2008: The Tinplate Company of India Limited- Neutral Trend following Nifty Trend. (Consistency score 7.0)

2006: Heavy Electrical Equipment Plant, BHEL, Haridwar - Outperformed but (Consistency score 12.0) underperforming since Nov 2011

(Note- BHEL award is only for one of units of BHEL)

Sample companies CS score that received CII/EFQM model award/ prize

(Figures given against the name are consistency score of the company computed by us)

Tube Investment 7 
BHEL 12

Crompton Grieves 12

Infosys 11

TCS 12

Tata Steel 11

Tin Plate 7

Fig 1 Comparison of price changes for S\&P CNX 500 and Nifty

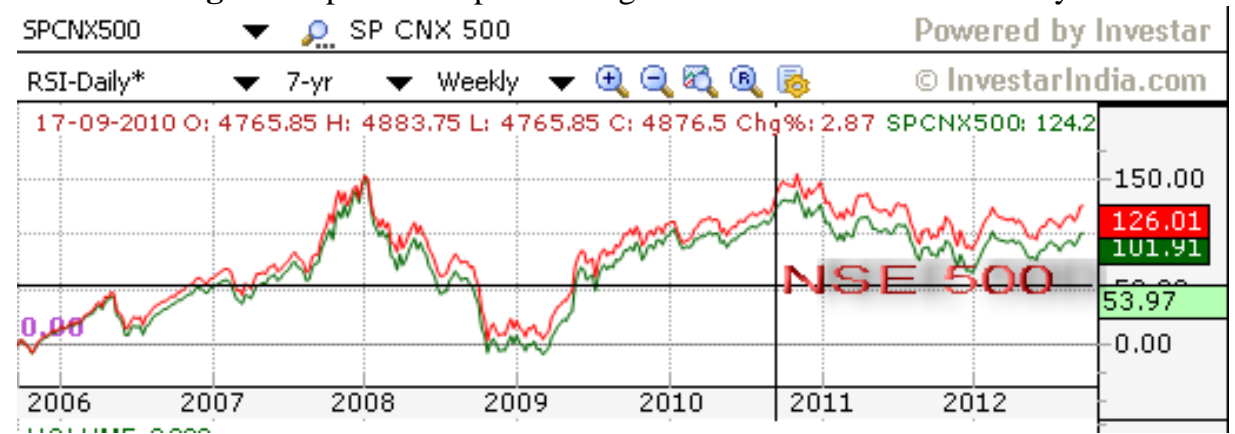

\section{Explanation of Graph:}

The change in prices has been taken as zero \% in beginning of 7 years period. The graph shows how the prices have changed in case of the two stocks, over the time. On 19-9-2012 the NSE 500 index has changed $101.91 \%$ from that value in 2005 and Nifty50 has changed 126\%. A look on the graphs shows that CNX500 and Nifty 50 both are following similar trend through out. Hence for further comparison we have taken most common Nifty 50 graph as base.

Fig 2 Comparison of price changes for Bosch Ltd and Nifty

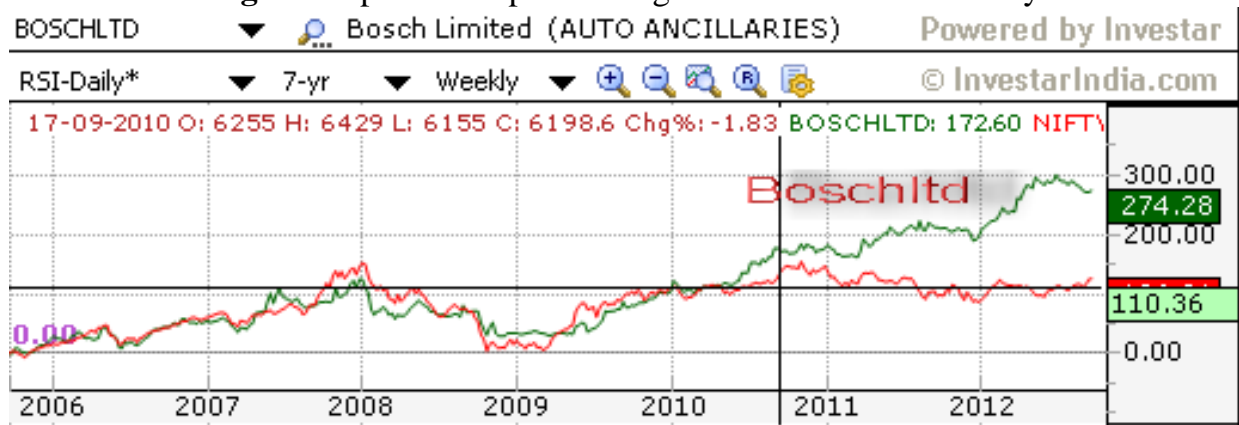

Fig 3 Comparison of price changes for BHEL and Nifty

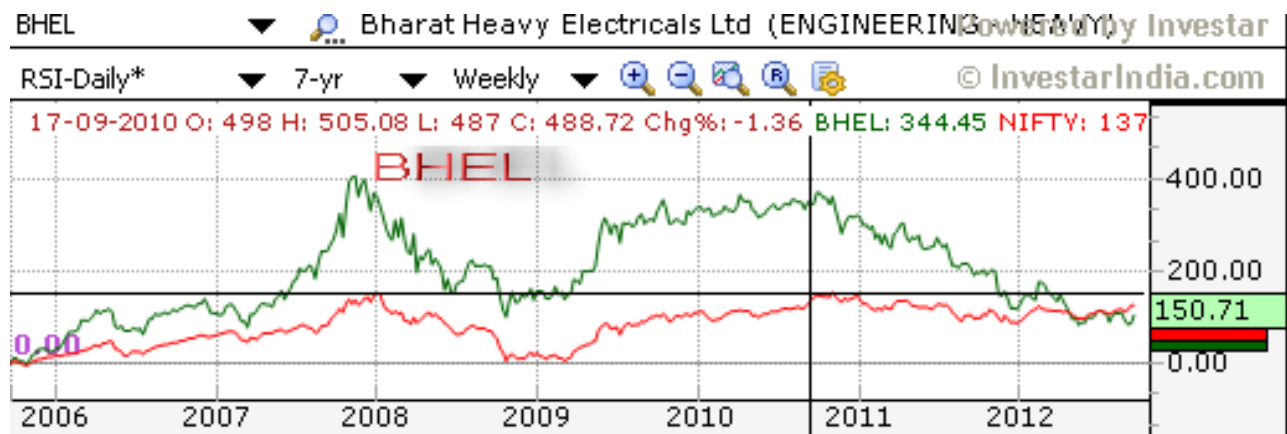

Fig 4 Comparison of price changes for Tinplate and Nifty 
Impact of Excellence Model awards on stock market performance - A study of selected Indian

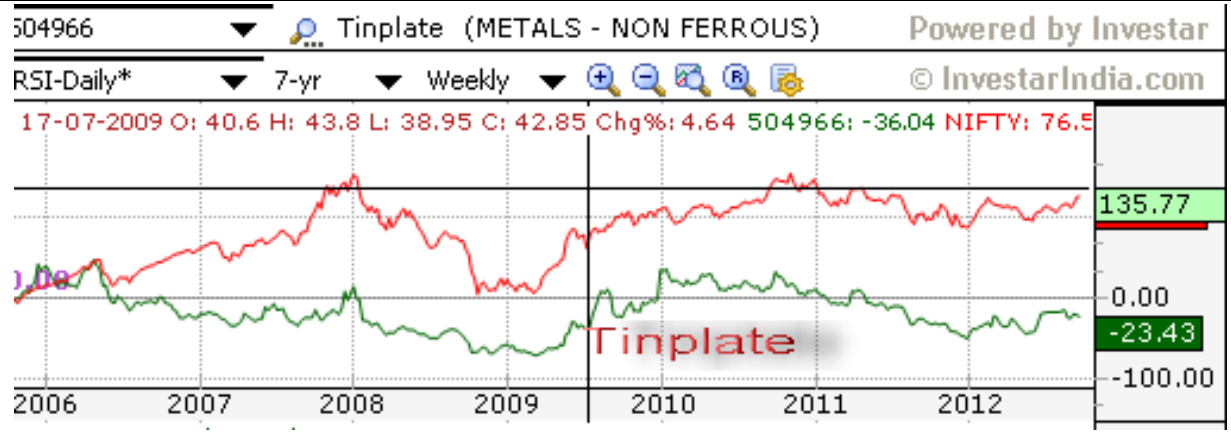

Fig 5 Comparison of price changes for Crompton Greaves and Nifty

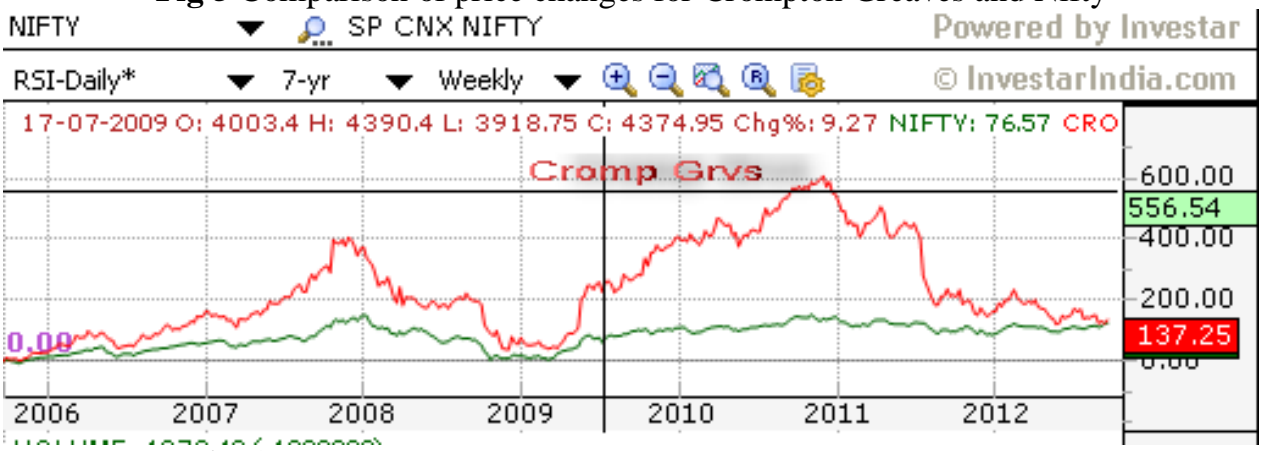

Fig 6 Comparison of price changes for Maruti Suzuki and Nifty

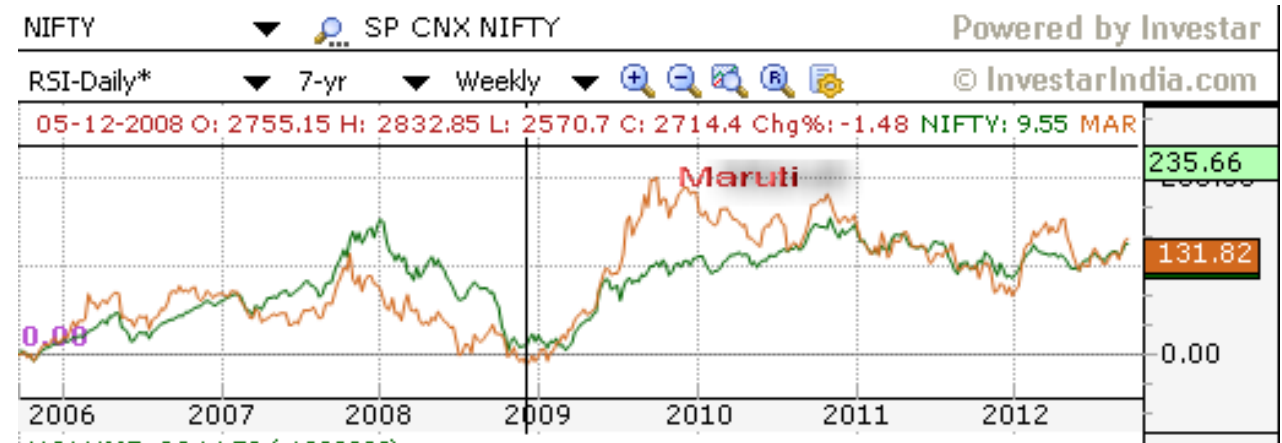

Fig 7 Comparison of price changes for Tata Steel and Nifty

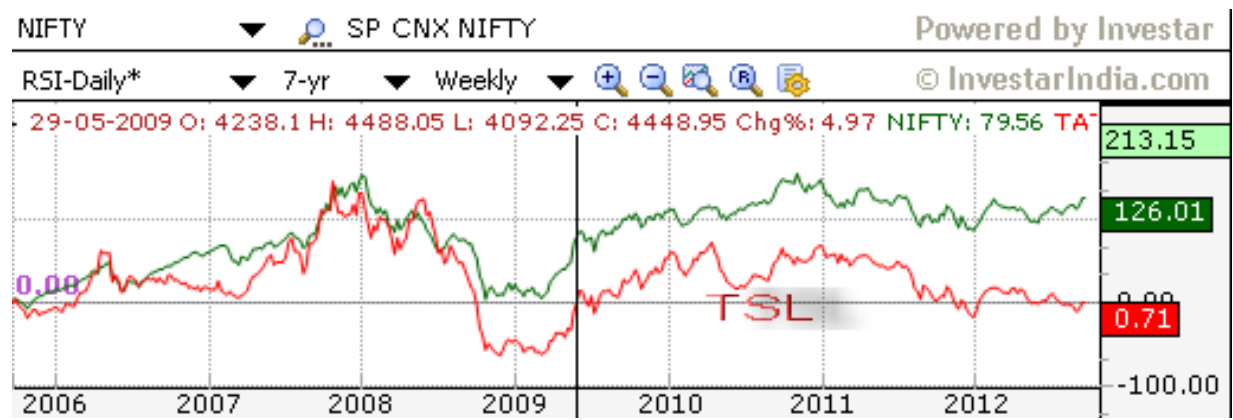

Fig 8 Comparison of price changes for TCS and Nifty

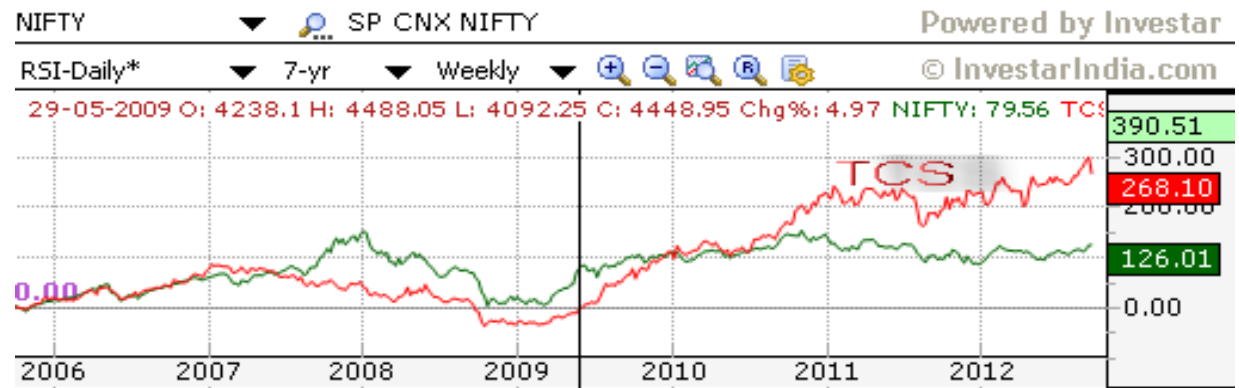

Fig 9 Comparison of price changes for Infosys and Nifty 


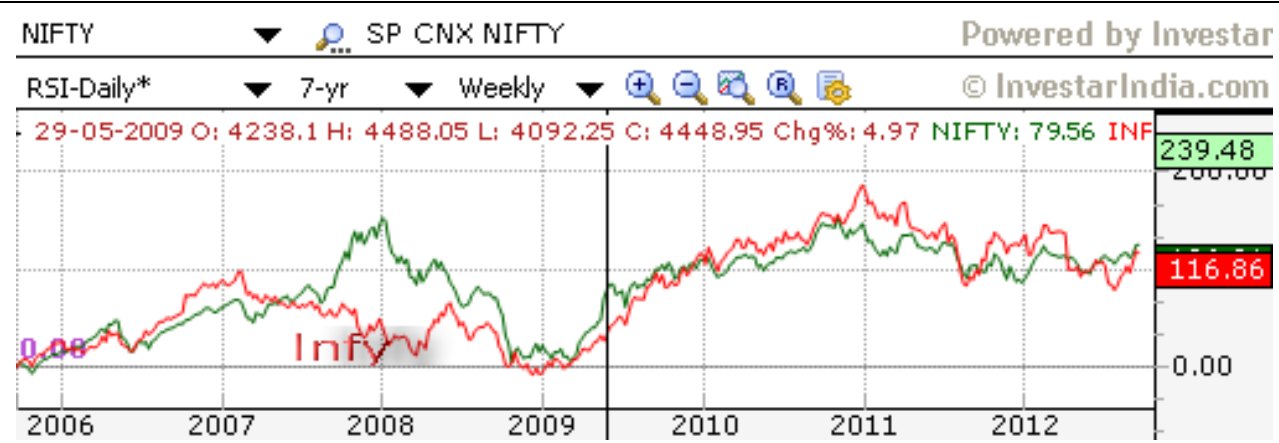

From perusal of above charts we can clearly see that only Bosch ltd, BHEL, Crompton Greaves, and TCS have given higher performance than the benchmark index. Companies like Tinplate, Infosys, and Tata Steel have been under performers.

\section{Conclusions:}

Hence the performance of those companies that have achieved excellence awards in India or excellence prizes do not show in clear terms that they gain advantage for shareholders in stock markets over benchmark indices. Even the computation of Consistency scores shows that Tata Steel and Tinplate Co of India have low CS of 7 which means these two companies have suffered negative growth in either profit or sales revenue in more than one financial year in last 5 years period. Incidentally both these companies belong to metals sector. Hence, our finding in Indian companies is not in conformity with studies made in USA and some other places. The two important reasons could be given. Either these companies do not seriously pursue and maintain standards of excellence practice once awards are given or the stock market performance depends more on macro economic factors and business cycles than company's own internal strengths as far as out performing stock markets is concerned. This may be one reason why many companies don't opt for qualifying for National Excellence model award.

However these companies are leaders in their own industry since these have been selected in the sample on this very criterion.

The present finding adds to debate going on about gains from excellence models in stock markets. If any company continuously registers consistency score of 9 or above (Maximum 12) for a few years then, it is a good company to invest from shareholders point of view. Of course companies that practice excellence, score high on business performance indicators indicating competitive strength, as was found in our main research study.

\section{References}

[1] Azaranga, Mohammad R. \& Gonzalez, Graciela (1998). An empirical investigation of the relationship between quality improvement techniques and performance -- a Mexican case. Journal of Quality Management; Vol. 3 Issue 2, p265, 1998

[2] Business Excellence Study 2011. Report of Asian Productivity Organization, 2011

[3] EFQM \& BQF funded study: Short Report; Organizational Excellence Strategies \& Improved Financial Performance. University of Leicester. Copyright 2005 EFQM and BQF.

[4] Halim Kazan, Gökhan Özer, Ayse Tansel Çetin. The effect of manufacturing strategies on financial performance, Measuring Business Excellence, Vol. 10 Iss: 1, pp.14-26.2006

[5] Hendricks, K.B. and Singhal, V. R. (2001a).Firms characteristics, total quality management and financial performance. Journal of Operations Management, 19,265-289

[6] Helton, R. (1995) The Baldie play. Quality Progress

[7] Hendricks, K.B. and Singhal, V. R. (2001b). The impact of TQM on financial performance: evidence from Quality award winners. In: Stakeholder value- The path to sustainable growth. Lucerne: EFQM

[8] NIST (2002). Baldrige winners beat the S\&P 500 for the Eighth year. National Institute for Standards \& Technology (www.Quality.nist.gov)

[9] Oakland Consulting: Is Business Excellence of Any Value? Does it generate and sustain organizational advantage? European centre for Business Excellence, ECforBE-2 - May 2005

[10] Porter, Les and Tanner, S.J. Assessing Business Excellence 2e. Elsevier. Reprint 2008

[11] Powell, T.C. (1995). TQM as competitive advantage. A review and empirical study. Strategic Management Journal, 16, 15-37

[12] Singhal, Vinod Dr. \& Hendricks (2000): The Impact of Total Quality Management (TQM) on Financial Performance: Evidence from Quality Award Winners; University of western Ontario 2001

[13] Tanner, Dr S J (2005). Is Business Excellence of any value? White paper for European Centre for Business Excellence ECforBE-2May 2005

[14] Przasnyski, Z.H. and Tai, L.S. (2002) Stock performance of Malcolm Baldrige award winning companies .Total Quality Management, 13(4), 475-488 